\title{
Correction
}

\section{Correction: Ledbetter et al., Multiple Mechanisms for Processing Reward Uncertainty in the Primate Basal Forebrain}

In the article "Multiple Mechanisms for Processing Reward Uncertainty in the Primate Basal Forebrain" by Noah M. Ledbetter, Charles D. Chen, and Ilya E. Monosov, which appeared on pages 7852-7864 of July 27, 2016 issue, the authors regret an error in Figures 7C-D, where the second $y$-axis tick mark was labeled as 0.5 . The label should have been $50 \%$. Figure 7 has been corrected on the online PDF version and displayed below.

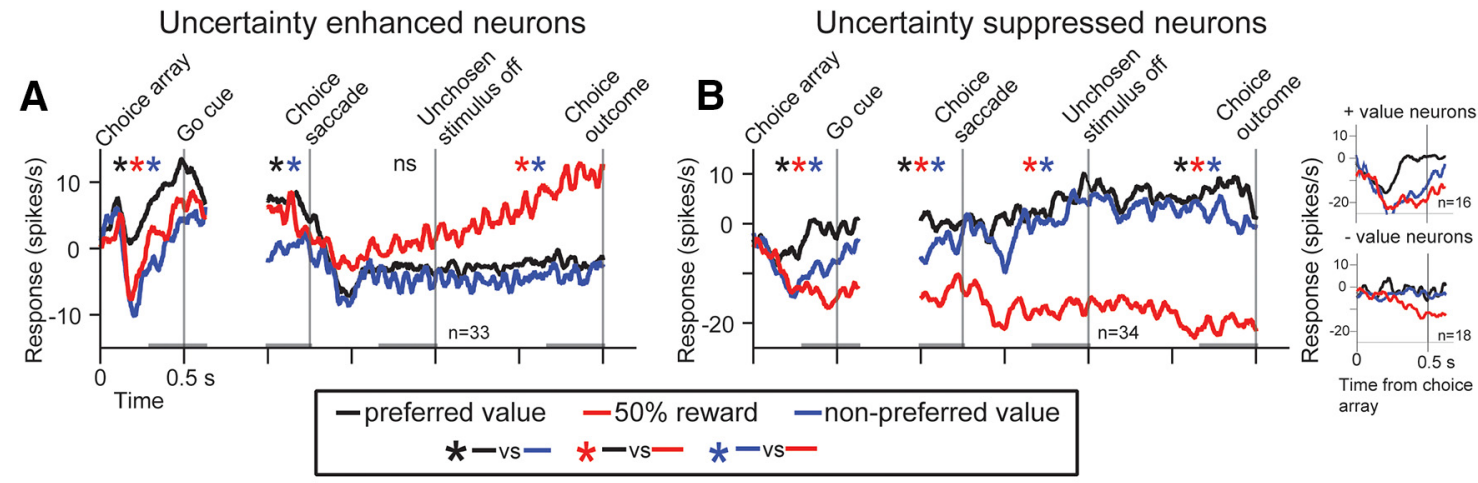

C

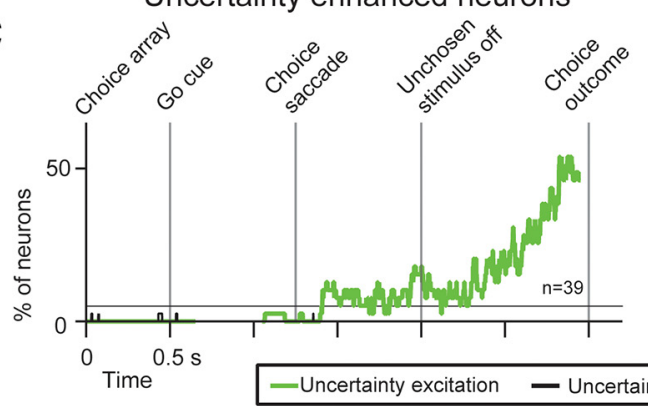

Uncertainty suppressed neurons

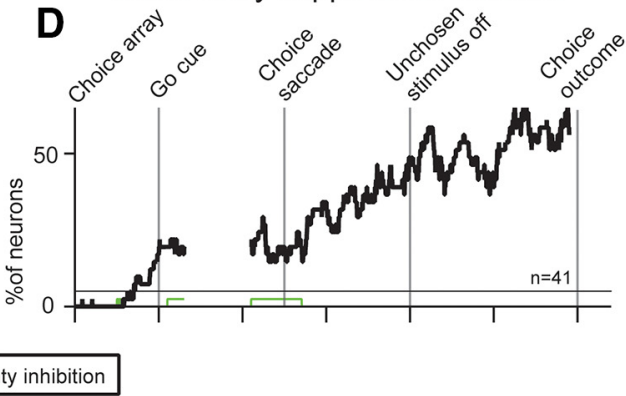

Figure 7.

DOI: 10.1523/JNEUROSCI.2846-16.2016 